\title{
The fate of the neoaortic valve and root after the modified Ross-Konno procedure
}

\author{
Bahaa M. Fadel, MD, ${ }^{\mathrm{a}}$ Cedric Manlhiot, BSc, ${ }^{\mathrm{b}}$ Zohair Al-Halees, MD, ${ }^{\mathrm{a}}$ Giovanni Di Salvo, MD, ${ }^{\mathrm{a}}$ \\ Mamdouh Al-Ahmadi, MD, ${ }^{\mathrm{a}}$ Brian McCrindle, MD, ${ }^{\mathrm{b}}$ and Bahaaldin Alsoufi, MD ${ }^{\mathrm{a}}$
}

Objectives: In children with aortic valve disease associated with annular hypoplasia or complex multilevel left ventricular outflow tract obstruction, the Ross procedure, combined with a modified Konno-type aortoventriculoplasty, is advocated. We aim to examine the fate of the neoaortic apparatus and assess neoaortic valve function after the modified Ross-Konno procedure.

\begin{abstract}
Methods: Forty-three patients, with a median age of 6 years, underwent the modified Ross-Konno procedure with a myectomy but without the use of a ventricular septal patch. Serial postoperative echocardiograms $(\mathrm{n}=187)$ were analyzed, and regression models adjusted for repeated measures were used to model the longitudinal growth of the neoaortic annulus and root.
\end{abstract}

Results: There were 2 operative deaths (5\%) and 1 late mortality. At 8 years, survival was $93 \%$ and freedom from autograft, homograft, and all-cause reoperation was $100 \%, 81 \%$, and $72 \%$, respectively. The median postprocedure diameter and $z$ score were $14 \mathrm{~mm}(7-21 \mathrm{~mm})$ and $+1.3(-3.0$ to +6.1$)$ for the neoaortic annulus and $21 \mathrm{~mm}(9-30 \mathrm{~mm})$ and $+1.6(-1.3$ to +4.1$)$ for the neoaortic root, respectively. Serial echocardiograms showed a progressive increase in annular $(+0.56 \mathrm{~mm} /$ year, $P<.001)$ and root $(+0.89 \mathrm{~mm} / \mathrm{year}, P<.001)$ diameters but little change in annular $(-0.07 /$ year, $P=.08)$ and root $(-0.002 /$ year, $P=.96) z$ scores. Autograft regurgitation developed in 9 patients; however, the degree and progression of regurgitation over time were not significant $(P=.22)$.

Conclusions: After the modified Ross-Konno procedure, the neoaortic annulus and root increased in size proportionately to somatic growth. Autograft regurgitation, usually mild and stable, developed in few patients, and none required autograft reoperation. Our findings support the use of the modified Ross-Konno as the procedure of choice in children with aortic valve disease and complex left ventricular outflow tract obstruction. (J Thorac Cardiovasc Surg 2013;145:430-7)

Supplemental material is available online.

Aortic valve replacement (AVR) may be required in children with significant irreparable aortic valve disease. In those with a small aortic annulus or multilevel left ventricular outflow tract obstruction (LVOTO), aortoventriculoplasty using the Konno technique is highly effective in enlarging the left ventricular outflow tract (LVOT) to enable postoperative relief of gradient, especially in children. ${ }^{1}$ The classic Konno procedure was originally used in conjunction with a prosthetic

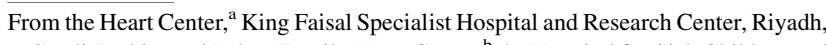

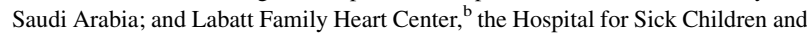
the University of Toronto, Toronto, Ontario, Canada.

Disclosures: Authors have nothing to disclose with regard to commercial support.

Read at the 38th Annual Meeting of The Western Thoracic Surgeons Association, Maui, Hawaii, June 27-30, 2012.

Received for publication May 21, 2012; accepted for publication July 9, 2012; available ahead of print Nov 16, 2012.

Address for reprints: Bahaaldin Alsoufi, MD, Heart Center (MBC 16), King Faisal Specialist Hospital and Research Center, PO Box 3354, Riyadh, Saudi Arabia 11211 (E-mail: balsoufi@hotmail.com).

$0022-5223 / \$ 36.00$

Copyright (c) 2013 by The American Association for Thoracic Surgery

http://dx.doi.org/10.1016/j.jtcvs.2012.07.004 valve insertion. ${ }^{1}$ Nonetheless, the use of prosthetic valves in the pediatric population is associated with many drawbacks, particularly in small children. ${ }^{2,3}$ The Ross procedure counters many of the disadvantages of prosthetic valves. It carries excellent hemodynamic characteristics and has a low risk of endocarditis or thromboembolism, thus allowing avoidance of anticoagulation requirement. ${ }^{4}$ The potential for autograft growth offers another key advantage of the Ross procedure in children requiring AVR. ${ }^{5,6}$ The addition of Konno-type aortoventriculoplasty in conjunction with the Ross procedure (Ross-Konno) has further allowed the successful management of small children with aortic valve disease associated with significant annular hypoplasia and complex LVOTO. ${ }^{2}$

Nonetheless, the risk of neoaortic root dilatation leading to neoaortic valve regurgitation or aneurysm formation necessitating surgical reintervention has emerged as a major concern after the Ross procedure. ${ }^{7,8}$ Patients who undergo the Ross-Konno procedure might be at a higher risk of developing those autograft complications because of the inherent disruption of the supporting aortic annular structure at the time of aortoventriculoplasty.

There is little information available regarding the fate of the neoaortic root and the function of the neoaortic valve 


\section{Abbreviations and Acronyms \\ $\mathrm{AR}=$ aortic regurgitation \\ AVR $=$ aortic valve replacement \\ HR = hazard ratio \\ LVOT $=$ left ventricular outflow tract \\ LVOTO $=$ left ventricular outflow tract obstruction \\ RV-PA = right ventricle to pulmonary artery \\ VSD $=$ ventricular septal defect}

after the Ross-Konno procedure. Previous studies have suggested that preoperative aortic insufficiency and dilatation of the aortic annulus with geometric mismatch between the aortic and pulmonary annuli were risk factors for disproportionate postoperative dilatation of the neoaortic apparatus after the Ross procedure. ${ }^{7,9-11}$ However, the findings of those studies might not necessarily apply to the patient population undergoing the Ross-Konno procedure who predominantly had preoperative stenosis and a small aortic annulus. The purpose of this study is to assess the outcomes of patients after the modified Ross-Konno procedure with particular emphasis on the fate of the neoaortic valve and root.

\section{MATERIALS AND METHODS Inclusion Criteria}

From 1994 to 2007, 43 consecutive patients underwent AVR plus annular enlargement using the modified Ross-Konno procedure at the King Faisal Specialist Hospital and Research Center in Riyadh, Saudi Arabia. Patients were identified using the hospital surgical database. Clinical, operative, and outcome data were abstracted from their medical records. Approval of this study was obtained from the research ethics board at the King Faisal Specialist Hospital and Research Center, and requirement for individual consent was waived for this observational study.

\section{Operative Details}

Midline sternotomy was performed, and standard cardiopulmonary bypass and myocardial protection techniques were used in all cases. After the aorta was opened, the aortic valve, subvalvular area, and LVOT were assessed for the possibility of valve repair. When replacement was deemed necessary, the aortic valve cups were cut out and aortic buttons containing the coronary artery ostia were excised. The pulmonary autograft was then explanted, and the muscle rim underneath the valve was thinned. With both the aortic and pulmonary valves removed, the right ventricular outflow tract and LVOT became widely exposed, which facilitated LVOT enlargement. Then the fibrous annulus of the aortic valve was divided, and extensive septal myectomy below the left/right commissure was performed. The muscle excision was often made easy by palpating the septum between the fingers to make sure that a ventricular septal defect (VSD) was not created while all levels of LVOT obstruction were relieved. If needed, myectomy was extended down into the left ventricular cavity. In 2 patients, resection of endocardial fibroelastosis was performed. The pulmonary autograft was implanted as a full root with coronary transfer in all cases. Right ventricle to pulmonary artery (RV-PA) continuity was established with a homograft $(\mathrm{n}=42)$ or Contegra (Medtronic Inc, Minneapolis, Minn) bovine jugular vein conduit $(\mathrm{n}=1)$. Mean homograft size was $20.5 \pm$ $3.5 \mathrm{~mm}$. Fresh homografts were used in $64 \%$ of cases, and cryopreserved homografts were used in $36 \%$ of cases. Pulmonary homografts were used in $67 \%$ of cases, and aortic homografts were used in $33 \%$ of cases. Homografts were not generally matched for the blood group of the patients.

Ten patients ( $23 \%$ ) required additional concomitant cardiac surgery, including mitral valve repair $(n=4)$, aortic arch reconstruction $(n=4)$, mitral valve replacement $(\mathrm{n}=1)$, pulmonary artery augmentation $(\mathrm{n}=1)$, and resection of ascending aortic aneurysm $(n=1)$. Immediate postoperative results were assessed in all patients in the operating room by means of transesophageal echocardiography.

\section{Follow-up}

Patients were evaluated clinically and by means of detailed echocardiography on discharge, at 6 weeks after the operation, at 6 months, and yearly thereafter. Late outcomes were determined from recent office visits at the King Faisal Specialist Hospital and Research Center or from direct correspondence with patients' families. Follow-up was complete in $96 \%$ of the patients. Median follow-up duration was 5.3 years and ranged up to 14 years.

\section{Echocardiography}

Serial echocardiographic data were collected for the immediate postoperative study and for all future studies during the follow-up period. There were a total of 187 studies performed in our patient cohort with a median of 5 studies per subject (range, 2-11 studies). All measurements were performed by an experienced cardiologist (B.M.F.), and the average of 3 independent measurements was recorded. The diameters of the neoaortic valve annulus and root were measured in the parasternal long-axis view. Grading of neoaortic valve regurgitation was performed using the color Dopplerderived ratio of the regurgitant jet width to the annular diameter in the parasternal long-axis view (aortic regurgitation $[\mathrm{AR}]$ ratio). According to the recommendations of the American Society of Echocardiography, AR ratios less than $0.25,0.25$ to $0.45,0.46$ to 0.64 , and 0.65 or greater were considered to represent mild, mild-moderate, moderate-severe, and severe regurgitation, respectively. ${ }^{12}$

\section{Statistical Analysis}

Data are presented as means with standard deviation, medians with minimum and maximum values, and frequencies as appropriate. Long-term survival and freedom from reoperations were estimated using the KaplanMeier method. Cox regression was used to determine independent predictors of late outcomes. Linear regression analysis, based on maximum likelihood estimates, adjusted for repeated measures with an autoregressive covariance structure, was used to determine trends over time for serial echocardiographic assessments of AR grade, neoaortic annulus diameter and $z$ score, and neoaortic root diameter and $z$ score. These models consider every measurement within each patient, as opposed to every patient, as an observation, increasing our available sample size from 43 to 187 observations. The correlation between observations is accounted for through the covariance structure. Each regression model included, in addition to specific patient identifier, the covariates of interest, the time since the modified Ross-Konno operation, and the interaction between the covariates of interest and the time since surgery. Clinical relevance of identified covariates on likelihood of selected outcomes was established by solving the regression equations for multiple "typical" test patients. All statistical analyses were performed using SAS statistical software v9.1 (SAS Institute, Inc, Cary, NC).

\section{RESULTS}

\section{Patient Characteristics}

There were 29 male patients $(67 \%)$. The median age at the time of the modified Ross-Konno procedure was 6 years (range, 15 days to 27 years). Underlying cardiac pathology was congenital LVOTO in 39 patients $(91 \%)$, endocarditis 
in 2 patients $(5 \%)$, rheumatic in 1 patient $(2 \%)$, and degenerative in 1 patient $(2 \%)$. Hemodynamic aortic valve dysfunction was primarily stenosis in 20 patients $(47 \%)$, mixed disease in 20 patients $(47 \%)$, and primary regurgitation in 3 patients $(6 \%)$.

\section{Clinical Outcomes}

There were 2 operative deaths $(5 \%)$ in infants who required concomitant mitral valve repair $(\mathrm{n}=1)$ and arch reconstruction plus mitral valve repair $(\mathrm{n}=1)$. In addition, there was 1 late death in 1 patient who had arch reconstruction at the time of the modified Ross-Konno procedure as a neonate and then required reoperation for ascending aorta and recurrent arch obstruction followed by a second reoperation for homograft change, after which he died. Overall 1 - and 10-year survival was $93 \%$.

During follow-up, 12 patients had 13 cardiac reoperations $(28 \%)$. Those reoperations included homograft change $(n=9)$, mitral valve repair $(n=2)$, repair of ascending aorta and recurrent arch obstruction $(\mathrm{n}=1)$, and permanent pacemaker insertion $(\mathrm{n}=1)$. Overall 8-year freedom from homograft replacement was $81 \%$. On multivariable analysis, risk factors for homograft replacement were later year of surgery (hazard ratio [HR], 3.3; $P=.03$ ) and additional cardiac surgery at the time of the modified Ross-Konno procedure (HR, 5.1; $P=.02$ ). Overall 10 -year freedom from all-cause cardiac reoperation was $72 \%$. On multivariable analysis, risk factors for cardiac reoperation were again later year of surgery (HR, 5.9; $P=.03$ ) (Figure E1, A) and additional cardiac surgery at the time of the modified Ross-Konno procedure (HR, 5.8; $P=.03$ ) (Figure E1, $B$ ). None of the patients required autograft reoperation during the follow-up.

\section{Changes in Echocardiographic Parameters During Follow-up}

Median postprocedure neoaortic annulus diameter and $z$ score were $14 \mathrm{~mm}(7-21 \mathrm{~mm})$ and $+1.3(-3.0$ to +6.1$)$, respectively, and median postprocedure root diameter and $z$ score were $21 \mathrm{~mm}(9-30)$ and $+1.6(-1.3$ to +4.1$)$, respectively.

Longitudinal analysis of repeated echocardiographic measures showed a progressive increase in neoaortic annulus diameter with time $(+0.56[0.06] \mathrm{mm} /$ year, $P<.001)$ (Figure 1, $A$ ). There was no difference in the neoaortic annulus diameter increase between patients who required cardiac reoperation and those who $\operatorname{did} \operatorname{not}(P=.56)$ or between those who had preoperative stenosis and those who had mixed disease or regurgitation $(P=.76)$. On the other hand, there was no significant increase in neoaortic annulus $z$ score with time $(-0.08[0.04] /$ year, $P=.08)$ (Figure 1, $B)$. Older patients started with a lower neoaortic annulus $z$ score immediately after the modified Ross-Konno procedure but had a trend for a more rapid increase in neoaortic annulus $z$ score with time $(P=.09)$ (Figure 2, $A)$. Furthermore, patients who
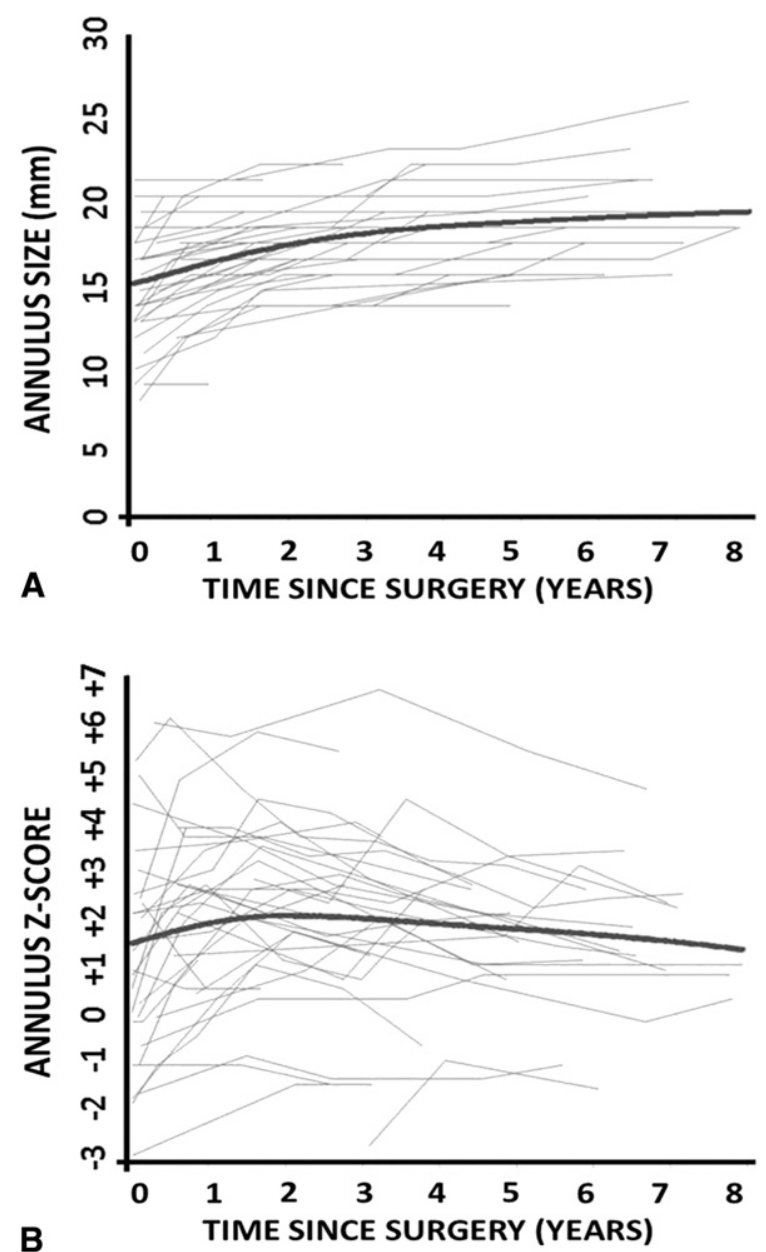

FIGURE 1. A, Trajectory of neoaortic annulus diameter growth over time is nonlinear and increases over time. The fine solid lines represent individual patient trajectories, and the heavy solid line is a smoothing spline that represents the best-fit average trend over time. Time zero was taken to be the date of the modified Ross-Konno procedure. B, Trajectory of neoaortic annulus $z$ score over time. The fine solid lines represent individual patient trajectories, and the heavy solid line is a smoothing spline that represents the best-fit average trend over time. Time zero was taken to be the date of the modified Ross-Konno procedure.

underwent additional cardiac surgery at the time of the modified Ross-Konno procedure had a faster increase in neoaortic annulus $z$ score with time $(P=.001)$ (Figure 2, $B)$.

There was a progressive increase in neoaortic root diameter with time $(+0.88[0.09] \mathrm{mm} / \mathrm{year}, P<.001)$ (Figure 3,A). There was no difference in the neoaortic root diameter increase between patients who required cardiac reoperation and those who did not $(P=.49)$ or between those who had preoperative stenosis and those who had mixed disease or regurgitation $(P=.72)$. On the other hand, there was no increase in neoaortic root $z$ score with time $(-0.002[0.04] /$ year, $P=.96)$ (Figure 3, $B)$. Older patients started with a lower neoaortic root $z$ score immediately after the modified Ross-Konno procedure but had a trend for 

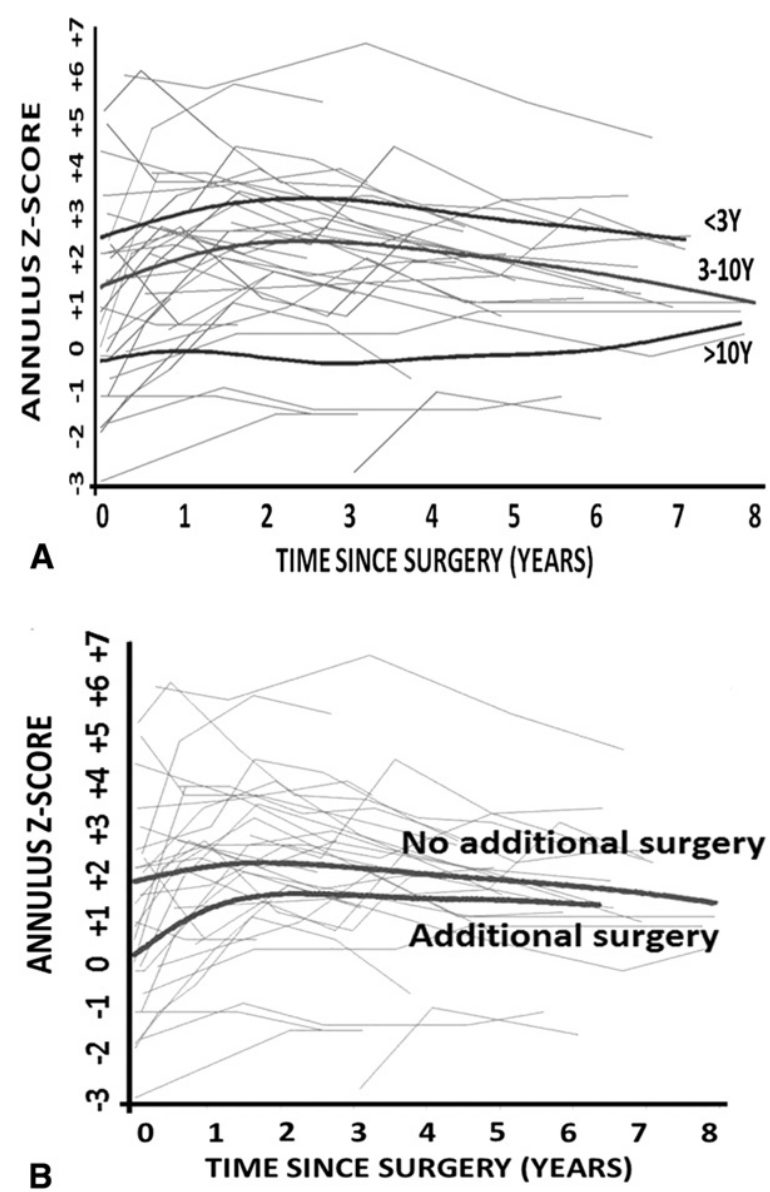

FIGURE 2. Trajectory of neoaortic annulus $z$ score over time stratified by (A) age group: Older patients start with a lower neoaortic annulus $z$ score immediately after the modified Ross-Konno procedure but have a trend for a more rapid increase in neoaortic annulus $z$ score with time; and (B) requirement for additional surgery at the time of the modified Ross-Konno procedure: Patients who underwent additional cardiac surgery at the time of the modified Ross-Konno procedure had a faster increase in neoaortic annulus $z$ score with time.

more rapid increase in neoaortic root $z$ score with time $(P=.004)$ (Figure 4).

Only 9 patients had immediate $(\mathrm{n}=7)$ or late $(\mathrm{n}=2)$ measurable neo-AR on follow-up. The degree of regurgitation was mild $(\mathrm{n}=7)$ or mild-moderate $(\mathrm{n}=2)$. This AR ratio was stable with time $(+0.001[0.001] /$ year, $P=.22)$ (Figure 5, A). There was no difference in the AR ratio increase between patients who required cardiac reoperation and those who did not $(P=.23)$ or between those who had preoperative stenosis and those who had mixed disease or regurgitation $(P=.27)$. Older patients had a trend for a more rapid increase in AR ratio with time $(P=.004)$ (Figure 5, $B)$.

\section{DISCUSSION}

AVR in children with a small aortic annulus or complex LVOTO has long posed a management challenge because


FIGURE 3. A, Trajectory of neoaortic root diameter growth over time is nonlinear and increases over time. The fine solid lines represent individual patient trajectories, and the heavy solid line is a smoothing spline that represents the best-fit average trend over time. Time zero was taken to be the date of the modified Ross-Konno procedure. B, Trajectory of neoaortic root $z$ score over time. The fine solid lines represent individual patient trajectories, and the heavy solid line is a smoothing spline that represents the best-fit average trend over time. Time zero was taken to be the date of the modified Ross-Konno procedure.

of technical difficulties and major drawbacks of different valve replacement options. ${ }^{4}$ The Ross procedure has emerged as the preferable alternative in children, especially in small infants because it was associated with low operative mortality, superior hemodynamic characteristics, minimal thromboembolic complications, and no anticoagulationrelated bleeding, all with consequent survival advantage over mechanical valves. ${ }^{2,13,14}$

In patients who have undergone AVR with a mechanical prosthesis, the risk of mortality and valve-related complications was highest in younger children receiving small prostheses. ${ }^{3,13,14}$ The modified Ross-Konno procedure allows the successful treatment of complex LVOTO in that particular high-risk subset of young patients and thus may 


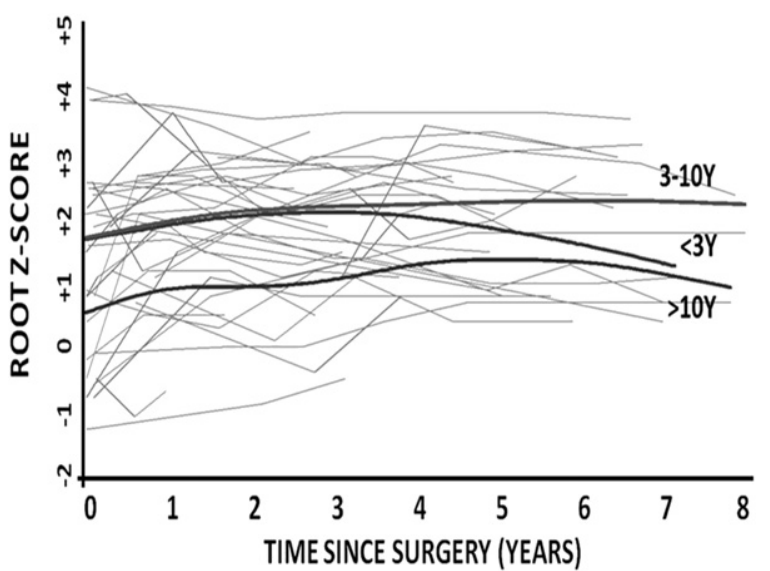

FIGURE 4. Trajectory of neoaortic root $z$ score over time stratified by age group: Older patients start with a lower neoaortic root $z$ score immediately after the modified Ross-Konno procedure but have a trend for a more rapid increase in neoaortic root $z$ score with time.

offer the highest survival advantage among children requiring AVR. ${ }^{13}$

\section{Mortality and Reoperation}

Despite surgical complexity, our study demonstrates that the modified Ross-Konno procedure can be performed with a low mortality risk. There were 2 operative deaths $(5 \%)$ in infants who required simultaneous mitral and aortic arch procedures. The only late death occurred in a patient who required late reoperation for recurrent arch obstruction. In a recent review of patients who had undergone the Ross procedure for congenital aortic valve disease, annular enlargement using the modified Ross-Konno was not associated with increased mortality risk; however, additional heart pathology apart from LVOTO and simultaneous cardiac procedures were major factors affecting early mortality and overall survival. ${ }^{15}$ Nonetheless, in properly selected patients, the mortality rate of those undergoing the modified Ross-Konno procedure remains favorable compared with young children who undergo the traditional Konno procedure with a prosthetic valve. ${ }^{13,14,16}$

Although none of the patients in the current series required late autograft reintervention, reoperations for RVPA conduit replacement continue to be the major downside of the Ross procedure. ${ }^{17}$ Risk factors for conduit change that have been identified in prior series include fresh, aortic and smaller homografts, concomitant surgery in addition to earlier surgery era. ${ }^{15}$ In the current series, later era was identified as a risk factor for conduit change and overall reoperation. That discrepancy with prior studies can be explained by the fact that there were more neonates and small infants who underwent the modified Ross-Konno operation in the most recent era $(25 \%$ neonates after 2001 vs $9 \%$ before 2001). Subsequently, there were more aortic homografts $(47 \%$ vs $26 \%$ ), smaller homografts (median $19 \mathrm{~mm}$
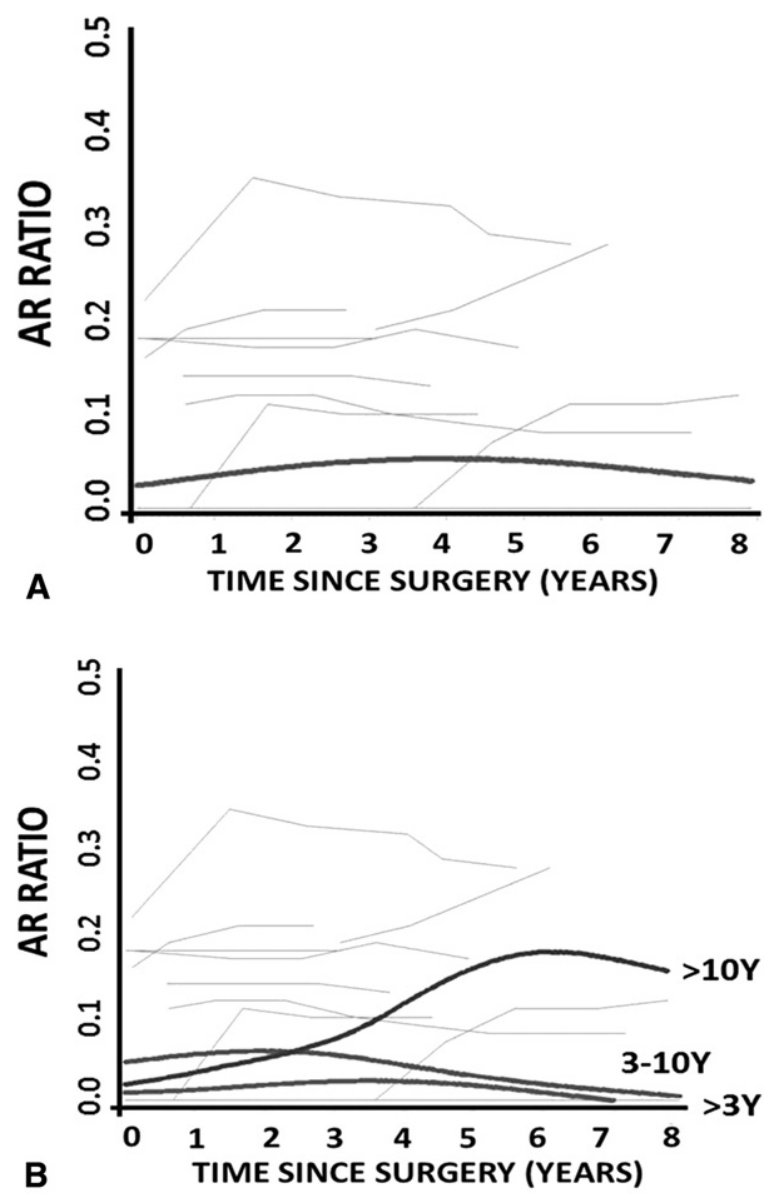

FIGURE 5. A, Trajectory of progression of AR jet width over LVOT diameter ratio (AR ratio): AR ratio was stable over time. The fine solid lines represent individual patient trajectories, and the heavy solid line is a smoothing spline that represents the best-fit average trend over time. Individual trajectories of patients with no regurgitation $(A R$ ratio $=0)$ overlap with the horizontal axis. Time zero was taken to be the date of the modified Ross-Konno procedure. B, Trajectory of progression of AR jet width over LVOT diameter ratio (AR ratio) over time stratified by age groups: Older patients had a trend for a more rapid increase in AR ratio with time. $A R$, Aortic regurgitation.

vs $23 \mathrm{~mm}$ ), and more concomitant surgery ( $44 \%$ vs $11 \%$ ) in patients who underwent surgery after 2001 as compared with those who underwent surgery before 2001. Nonetheless, mortality risk for conduit replacement has been low, and the advent of percutaneous pulmonary valve implantation techniques currently allows management of RV-PA conduit pathology without the need for surgery in many patients with late conduit dysfunction after the Ross procedure. ${ }^{17}$

\section{Fate of the Neoaortic Annulus and Root}

A key advantage of the Ross procedure in children is the growth potential of the neoaortic annulus and root because of the preserved autograft viability. ${ }^{5,6,18}$ It remains debatable whether the neoaortic apparatus enlargement 
after the Ross procedure is actual growth in a manner proportional to somatic growth or pathologic remodeling with disproportionate and excessive dilatation. ${ }^{5,6,18-22}$ Most important, data regarding the fate of the neoaortic apparatus in the subset of patients who underwent the Ross-Konno procedure remain scarce. Our findings suggest that the predominant mechanism for the increase in neoaortic annulus and root diameters after the modified Ross-Konno procedure was growth rather than dilatation. Neoaortic growth was associated with preserved autograft valve function, with few patients having mild regurgitation that did not increase in severity with longer follow-up.

Similar to patients undergoing the Ross procedure, patients undergoing the Ross-Konno procedure may be predisposed to future adverse remodeling of the neoaortic apparatus, theoretically more so than those after the Ross procedure alone. The incision across the aortic annulus during the Konno aortoventriculoplasty may result in destabilization of the supporting annular structure of the neoaortic apparatus, which may lead to abnormal remodeling and dilatation of the neoaortic apparatus with subsequent autograft valve insufficiency.

The modified Ross-Konno procedure without placement of a ventricular septal patch offers complete relief of LVOTO comparable to that of the traditional Ross-Konno with ventricular septal patch insertion. ${ }^{11,19-21}$ Nonetheless, this modification might provide better preservation of the annular structure than the traditional Ross-Konno procedure. In a series from Philadelphia, a prior VSD patch was identified as a risk factor for neoaortic valve regurgitation and reintervention. ${ }^{22}$ The absence of a VSD patch in the modified Ross-Konno procedure might have contributed to the favorable findings of stable neoaortic root and annulus $z$ scores, and the relative preservation of neoaortic valve function in our series.

Several groups of patients have been identified to be at increased risk for dilatation of the neoaortic apparatus and subsequent neoaortic valve regurgitation after the Ross procedure, including patients with preoperative AR, dilated aortic annulus, and geometric mismatch between the original aortic root and the pulmonary autograft. ${ }^{7,10,11,23}$ The favorable echocardiographic findings in our series may be explained by multiple factors. None of our subset of patients with a small aortic annulus requiring Konno aortoventriculoplasty naturally had a geometric mismatch between the aortic and pulmonary valves with an aortic annulus larger than the pulmonary valve. In addition, only 3 of our patients had pure regurgitation before surgery. Moreover, the presence of severe aortic stenosis in the majority of patients, with many having multilevel LVOTO, may have been associated with preoperative pulmonary hypertension. Pulmonary hypertension may have led to "priming" of the pulmonary root through structural changes in its wall, thus allowing it to better adapt to the systemic blood pressure once it was transitioned into the aortic position. ${ }^{22}$

Other patient characteristics, such as age at surgery and postoperative hemodynamics, likely play a role in future neoaortic root dilatation. ${ }^{24}$ Although our data showed that the increase in the neoaortic annulus and root dimensions was proportional to somatic growth, older patients in our series had a trend for a faster increase in those dimensions. We hypothesize that the pulmonary autograft may better adapt to the higher pressure in the aorta when it is transitioned to the aortic position early at a younger age when smooth muscle cells are more prone to differentiation and hyperplasia, thus allowing for the required structural changes in its wall to withstand aortic pressure. The autograft wall in older patients with higher systemic blood pressure might withstand higher wall stress, which could offer a stimulus for adverse remodeling and dilatation.

Only a minority of patients in our series $(5 \%)$ experienced neoaortic valve regurgitation more than mild, and none required autograft reoperation during our follow-up interval. In 7 patients in whom mild $(n=5)$ or mildmoderate $(\mathrm{n}=2)$ postoperative regurgitation developed, neoaortic valve regurgitation remained stable and did not worsen over time. Similar to our findings with the neoaortic annulus and root, there was a trend for a more rapid increase in the degree of autograft regurgitation in older patients, although the increase was not statistically significant. Our observation demonstrates the association between the increase in neoaortic root diameter and the development and progression of neoaortic valve regurgitation. Dilatation of the annulus often leads to stretching of the neoaortic cusps with subsequent autograft regurgitation because of the lack of coaptation.

\section{CONCLUSIONS}

The modified Ross-Konno procedure may be required in patients with aortic stenosis associated with small aortic annulus or multilevel LVOTO. The neoaortic apparatus continues to grow after the modified Ross-Konno procedure; however, a stable annulus and root $z$ score indicate that this growth is proportional to somatic enlargement with rare development of undue pathologic dilatation. The function of the aortic autograft in this subset of patients with predominantly preoperative aortic stenosis is long-lasting with no or minimal regurgitation in the majority of patients and no requirement for late autograft reintervention. These findings support the use of the modified Ross-Konno procedure as the aortic valve substitute of choice in children with severe annular hypoplasia or complex LVOTO.

\section{References}

\footnotetext{
1. Konno S, Imai Y, Iida Y, Nakajima M, Tatsuno K. A new method for prosthetic valve replacement in congenital aortic stenosis associated with hypoplasia of the aortic valve ring. J Thorac Cardiovasc Surg. 1975;70:909-17.
} 
2. Erez E, Kanter KR, Tam VK, Williams WH. Konno aortoventriculoplasty in children and adolescents: from prosthetic valves to the Ross operation. Ann Thorac Surg. 2002;74:122-6.

3. Turrentine MW, Ruzmetov M, Vijay P, Bills RG, Brown JW. Biological versus mechanical aortic valve replacement in children. Ann Thorac Surg. 2001;71: S356-60.

4. Khwaja S, Nigro JJ, Starnes VA. The Ross procedure is an ideal aortic valve replacement operation for the teen patient. Semin Thorac Cardiovasc Surg Pediatr Card Surg Anпи. 2005;173-5.

5. Solymar L, Südow G, Holmgren D. Increase in size of the pulmonary autograft after the Ross operation in children: growth or dilation? J Thorac Cardiovasc Surg. 2000;119:4-9.

6. Simon P, Aschauer C, Moidl R, Marx M, Keznickl FP, Eigenbauer E, et al. Growth of the pulmonary autograft after the Ross operation in childhood. Eur J Cardiothorac Surg. 2001;19:118-21.

7. Laudito A, Brook MM, Suleman S, Bleiweis MS, Thompson LD, Hanley FL, et al. The Ross procedure in children and young adults: a word of caution. J Thorac Cardiovasc Surg. 2001;122:147-53.

8. David TE, Omran A, Ivanov J, Armstrong S, de Sa MP, Sonnenberg B, et al. Dilation of the pulmonary autograft after the Ross procedure. J Thorac Cardiovasc Surg. 2000;119:210-20.

9. Takkenberg JJ, van Herwerden LA, Galema TW, Bekkers JA, KleyburgLinkers VE, Eijkemans MJ, et al. Serial echocardiographic assessment of neoaortic regurgitation and root dimensions after the modified Ross procedure. J Heart Valve Dis. 2006;15:100-6.

10. Alsoufi B, Manlhiot C, Fadel B, Al-Ahmadi M, Tamim M, McCrindle BW, et al. The Ross procedure in children: preoperative haemodynamic manifestation has significant effect on late autograft re-operation. Eur J Cardiothorac Surg. 2010;38:547-55.

11. Reddy VM, McElhinney DB, Phoon CK, Brook MM, Hanley FL. Geometric mismatch of pulmonary and aortic annuli in children undergoing the Ross procedure: implications for surgical management and autograft valve function. J Thorac Cardiovasc Surg. 1998;115:1255-62.

12. Zoghbi WA, Enriquez-Sarano M, Foster E, Grayburn PA, Kraft CD, Levine RA, et al. Recommendations for evaluation of the severity of native valvular regurgitation with two-dimensional and Doppler echocardiography. J Am Soc Echocardiogr. 2003;16:777-802.

13. Alsoufi B, Al-Halees Z, Manlhiot C, McCrindle BW, Al-Ahmadi M, Sallehuddin A, et al. Mechanical valves versus the Ross procedure for aortic valve replacement in children: propensity-adjusted comparison of long-term outcomes. J Thorac Cardiovasc Surg. 2009;137:362-70.

14. Karamlou T, Jang K, Williams WG, Caldarone CA, Van Arsdell G, Coles JG, et al. Outcomes and associated risk factors for aortic valve replacement in 160 children: a competing-risks analysis. Circulation. 2005;112:3462-9.

15. Alsoufi B, Al-Halees Z, Manlhiot C, McCrindle BW, Kandeel M, Al-Joufan M, et al. Superior results following the Ross procedure in patients with congenital heart disease. J Heart Valve Dis. 2010;19:269-77.

16. Mavroudis C, Backer CL, Kaushal S. Aortic stenosis and aortic insufficiency in children: impact of valvuloplasty and modified Ross-Konno procedure. Semin Thorac Cardiovasc Surg Pediatr Card Surg Annu. 2009;76-86.

17. Alsoufi B, Fadel B, Bulbul Z, Al-Ahmadi M, Al-Fayyadh M, Kalloghlian A, et al. Cardiac reoperations following the Ross procedure in children: spectrum of surgery and reoperation results. Eur J Cardiothorac Surg. 2012; 42:25-31.

18. Elkins RC, Knott-Craig CJ, Ward KE, McCue C, Lane MM. Pulmonary autograft in children: realized growth potential. Ann Thorac Surg. 1994;57: 1387-93.

19. Brown JW, Ruzmetov M, Vijay P, Rodefeld MD, Turrentine MW. The RossKonno procedure in children: outcomes, autograft and allograft function, and reoperations. Ann Thorac Surg. 2006;82:1301-6.

20. Ohye RG, Gomez CA, Ohye BJ, Goldberg CS, Bove EL. The Ross/Konno procedure in neonates and infants: intermediate-term survival and autograft function. Ann Thorac Surg. 2001;72:823-30.

21. Hraska V, Krajci M, Haun CH, Ntalakoura K, Razek V, Lacour-Gayet F, et al. Ross and Ross-Konno procedure in children and adolescents: mid-term results. Eur J Cardiothorac Surg. 2004;25:742-7.

22. Pasquali SK, Cohen MS, Shera D, Wernovsky G, Spray TL, Marino BS. The relationship between neo-aortic root dilation, insufficiency, and reintervention following the Ross procedure in infants, children, and young adults. J Am Coll Cardiol. 2007;49:1806-12.
23. Elkins RC, Lane MM, McCue C. Ross operation in children: late results. J Heart Valve Dis. 2001;10:736-41.

24. Luciani GB, Favaro A, Casali G, Santini F, Mazzucco A. Ross operation in the young: a ten-year experience. Ann Thorac Surg. 2005;80:2271-7.

\section{Discussion}

Dr Ivan M. Rebeyka (Edmonton, Alberta, Canada). Your report of 43 patients who underwent a Ross-Konno procedure at a median age of 6 years is especially noteworthy for the $0 \%$ need for autograft reoperation at 8 years follow-up. Despite an increase in the aortic annular diameter from 14 to $21 \mathrm{~mm}$, there was no significant change in autograft annular root diameter when standardized by $Z$ score.

I have 3 short questions. Because these results seem to be significantly better when compared with previous reports with respect to the need for autograft reoperation, do you think there are specific details regarding your operative technique or postoperative management that may account for your superior results or is it simply because few of your patients had predominant AR as the initial lesion?

Dr Alsoufi. This subset of patients by definition did not have pure AR or aortic annulus dilatation. Both dilated aortic annulus and pure regurgitation are established risk factors for late autograft failure, so that alone might have contributed to the superior outcomes in our series. We and other groups have shown that the Ross procedure for aortic stenosis is associated with improved freedom from autograft reoperation, so the type of patients does play a role in the freedom from late autograft failure and reoperation.

As for the technical aspect, our modified Ross-Konno technique without using a VSD patch might have contributed to those superior outcomes. Several groups have shown that cutting into the annulus and placing a VSD patch might disrupt the annular support, which might contribute to future neoaortic annulus dilatation, regurgitation, and failure. The modification of the Ross-Konno that we have adopted might have contributed to those superior outcomes by preserving the annular support by not performing a large incision into the septum and not placing a VSD patch.

One more technical consideration that we have adopted is that the proximal suture line should be to the actual annulus rather than to the remnants of the aortic wall, which might protect against late dilatation.

Dr Rebeyka. Your article indicated that fresh as opposed to cryopreserved homografts were used in approximately two thirds of the patients. Although fresh homografts are not readily available in North America, I was interested if you were able to identify a difference in homograft function and longevity compared with the cryopreserved homograft that you used in the other third of the patient group.

Dr Alsoufi. You are talking about the RV-PA homograft of course?

Dr Rebeyka. Correct.

Dr Alsoufi. The main focus in the current series was not to assess the fate of the pulmonary homograft. However, we have looked at that in the past in larger series including all children who have undergone the Ross procedure. In those prior series, we found that pulmonary homografts were superior to aortic 
homografts, cryopreserved homografts were superior to fresh homografts, and longer follow-up was associated with more homograft reoperations. One technical modification we have used might have contributed to improved homograft longevity. We currently try to trim the muscle rim underneath the pulmonary valve to a only a few millimeters, which has been shown to decrease the risk of late homograft failure.

Dr Rebeyka. That is interesting because your article also seemed to demonstrate a difference in overall conduit reoperation rate when stratified by surgical era with worse outcomes more recently, and you had a 0\% 5-year operation rate in 1995 to 2000 and a $60 \%$ reoperation rate in 2004 to 2007 . Do you have any explanation or insight regarding the increased overall reoperation rate in the more recent era?

Dr Alsoufi. That's true, and the reason for that discrepancy is the fact that in the most recent era, we have operated on younger and smaller patients and subsequently have used smaller homografts, more fresh and more aortic homografts, which are all risk factors for homograft failure. Nonetheless, I believe that the larger prior series that I've mentioned are more powered to accurately assess factors affecting homograft survival.

Dr Ross Ungerleider (Winston Salem, NC). You have added so much to the field over the years, and this is another addition.

Two quick questions for you. I am intrigued, especially for your patients aged less than 3 years, with the application of your modified procedure where you do not cut into the interaventricular septum. I wonder if the Ross-Konno you are describing in this article (ie, the modified one) is just a subset of your Ross-Konnos, because there certainly are babies with an enormous size mismatch between a small aortic annulus and the larger pulmonary valve where I cannot imagine that you could translocate the pulmonary valve over to the aortic position without doing some of the typical ventricular incision. Are these just some of your Ross-Konno procedures? Do you do some standard Ross-Konno procedures for the babies with the big mismatch, or are you finding you can do these even in the babies with a big mismatch?

Dr Alsoufi. This modified technique has been applied to all our Ross-Konno cases who needed annular enlargement.

Dr Ungerleider. The other question I have relates to the lack of disruption of the annulus. As I understand, you believe this contributes to the protection of the autograft from dilatation because the $Z$ score values would make you think this is growth. However, in adult patients who receive Ross procedures there is no disruption of the annulus, and yet it is clear that they do have autograft dilatation because their $Z$ scores go up. Just speculate, why would you have protection against autograft dilatation in infants and not have protection in older patients, and at what age do you think that lack of protection occurs?

Dr Alsoufi. It is our hypothesis that the relative preservation of annular support in the modified Ross-Konno might offer an advantage over the standard Ross-Konno. However, there are definitely multiple factors that play a role in late neoaortic annular dilatation. Even though you preserve the annulus in older patients who do not require annular enlargement, there is probably a higher subset of those patients who had pure AR, which is a risk factor for neoaortic annular dilatation and autograft failure. Likewise, series of older cohorts include more patients with a discrepancy between the semilunar valves with the aortic valve annulus larger than the pulmonary valve, patients with bicuspid aortic valve with regurgitation, and patients with rheumatic fever. All of those risk factors are more present in the larger population than in the Ross-Konno population of almost a homogenous group of small patients with pure stenosis or mixed disease. So other risk factors do interplay in the risk of aortic annulus and root dilatation.

In addition, when you perform the Ross-Konno operation and use the pulmonary autograft early in younger patients with significant LVOTO, most of those patients may have more pulmonary hypertension than adult patients. So when you transfer that pulmonary autograft to the aortic position at an early age, maybe it is more primed to adapt to the systemic circulation than if you do it in an older patient without pulmonary hypertension. Maybe that affects the autograft remodeling. Another theory is that the higher blood pressure the autograft is exposed to in older patients might also contribute at least to a more significant passive early dilatation.

All of those remain theories, and we cannot have a definitive answer. Nonetheless, your comment underscores that there are several factors that affect late dilatation of the neoaortic annulus and root. 

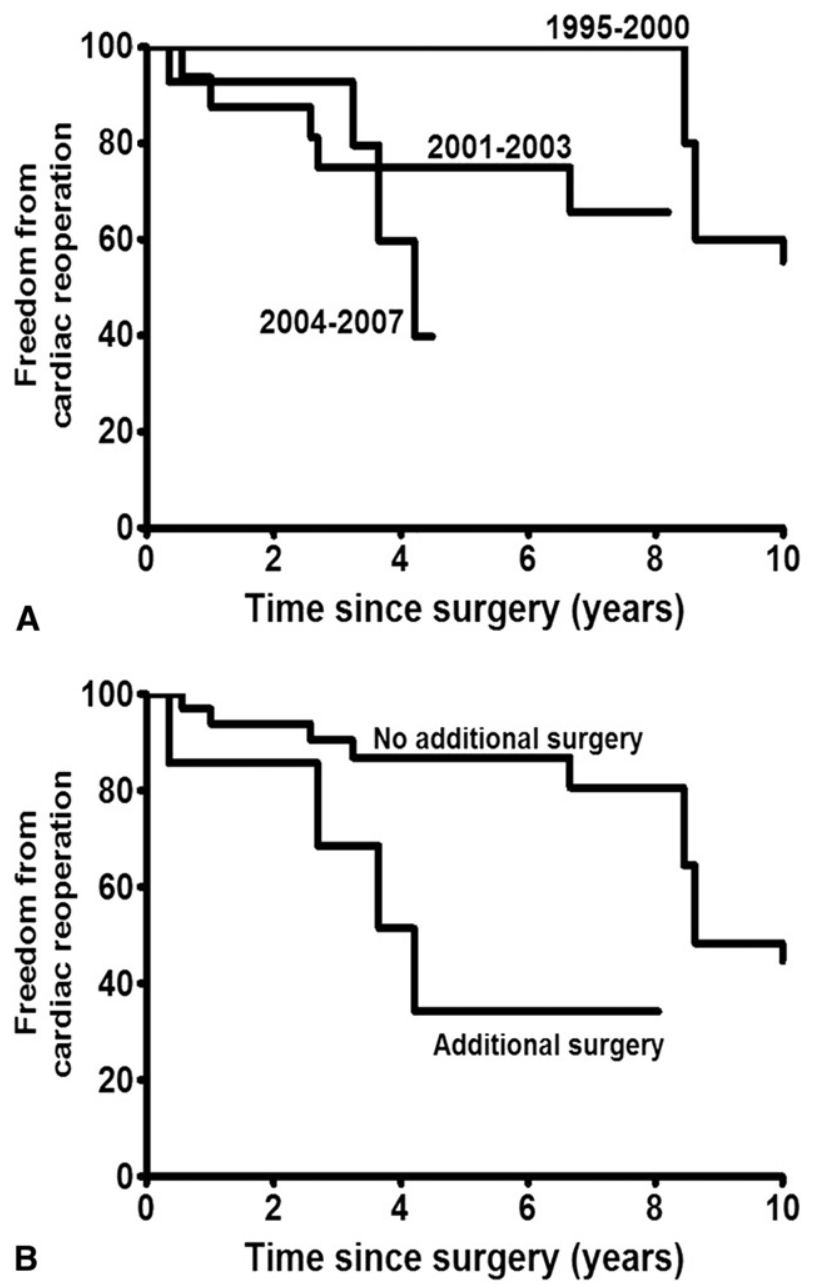

FIGURE E1. Time-related freedom from all-cause cardiac reoperation after the modified Ross-Konno procedure stratified by surgical era (A) and requirement of additional surgery at the time of the modified Ross-Konno procedure (B). 